\title{
Internet addiction: where we are now
}

\author{
J. Morahan-Martin \\ Department of Applied Psychology, Bryant University, Smithfield, USA
}

\begin{abstract}
This paper provides an overview of research on Internet Abuse (IA) and its relationship with other disorders. It suggests that it is important to differentiate between IA and Internet-enabled pathologies such as sexual paraphilias and pathological gambling which are performed online. Those who develop IA are drawn to the socially interactive aspects of the Internet, and find their social interactions are enhanced online compared to offline. A comprehensive model proposed by Caplan suggests that those who lack self-presentational skills develop a preference for online over face-to-face communication which leads them to use online communication compulsively which in turn leads to IA. This may explain the increased vulnerability for IA among those who are chronically lonely and socially anxious. Criticisms of this research are discussed.

Keywords: Internet addiction, Internet abuse, pathological Internet use, disturbed Internet use, psychopathology, social anxiety, loneliness, depression, impulse control disorder, addiction.
\end{abstract}

\section{Introduction}

Reports of Internet abuse began to surface in the early 1990s when chroniclers of social aspects of Internet use such as Rheingold [1] and Turkle [2] described a small group of users whose use of the Internet was out of control and an addictive quality. With the rapid spread of the Internet from a select group of scientists, mathematicians and computer experts into the general public, media reports began to surface about Internet addiction [3]. By the mid 1990s, research began appearing in academic journals $[4,5]$. In response to the perceived need, treatment centers specializing in computer and Internet addiction were developed; for example, the Computer Addiction Service at McLean Hospital, a Harvard Medical School teaching affiliate, was founded in 1996. The online Internet Addiction Disorder Support Group flourished even though its founder, 
Ivan Goldberg set it up as a joke [6]. Since then, Internet abuse has been documented worldwide and research on Internet abuse has proliferated. Clinics for Internet addiction have opened in many countries. The South Korean government plans to increase the number of treatment centers for Internet addicts from 40 to 100 by 2010 [7] while in the People's Republic of China, the first officially licensed government clinic for Internet addiction was opened in 2004 at the Beijing Military Region Central Hospital [8].

The concept of Internet addiction has not been without its critics though. Many are skeptical about the existence of Internet addiction. Critics have questioned the concept of Internet addiction and some have dismissed research on the topic [9-12]. This paper will present an overview on research on Internet abuse and criticisms of that research. Specifically, it will examine how Internet abuse (IA) has been defined, its relationship with other problems, and emerging theories about the etiology of Internet abuse.

\section{What is Internet abuse?}

There is a general agreement that IA that heavy use of the Internet alone does not qualify as IA, but rather that IA involves using Internet that leads to negative outcomes in an individual's life. However, varied names and specific criteria have been used to describe IA. Terms include Internet addiction [5, 13-17], Internet dependency [4, 18-20], pathological Internet use [21, 22], and problematic Internet use [23-27]. In this paper, the term Internet abuse (IA) is used throughout except when appropriate to use specific author's terminology.

In part, these terms reflect varying conceptualizations of IA. Often, IA has been treated as a clinical entity. Some have established criteria by modifying Diagnostic and Statistical Manual of Psychiatric Disorders (DSM) [28] criteria for substance abuse [4, 29] or pathological gambling [30]. Others have argued that IA should be considered an impulse control disorder not otherwise specified (NOS) [27, 31, 32] or as a behavioral or technological addiction [33].

Other researchers have viewed IA not so much as a clinical entity, and treated Internet-related behaviors more on a continuum of behaviors from normal to disturbed (e.g. [23-25]).

\section{Criticisms of diagnosis of IA}

Critics have questioned the appropriateness of applying any pathological label for Internet behavior [9, 12]. Grohol [9] has argued that the Internet is no more addictive or compulsive than other leisure activities such watching television, talking on the telephone or other leisure activities. Although people engage in these activities to the point of interrupting other aspects of their lives, there is little alarm about television or telephone addiction [34]. Turkle [2] argues that widespread alarm about IA may reflect fears about the rapid spread of new technology by people who are intimidated by that technology. 
Further, focusing blame on the Internet rather than the specific online activity that is causing problems is misleading. The problem is not the Internet per se, but the specific activities that people pursue online [11].

Other critics have questioned the appropriateness of applying the addiction model to IA [12]. Walther and Reid [12] contend that "we should not use valueladen terms such as addiction to label something we know so little about" (p. B5). Broadening addiction from substances to behaviors is controversial. Since the 1970s, there has been a trend to label disturbed patterns of behaviors such as eating, exercise, television, shopping, computer games, gambling, and sex as addicted (e.g., [35-38]. Jaffe [39]) argues that the broadened use of the term "addiction" trivializes the concept of substance-related addiction, and is detrimental to understanding specific etiology and treatment approaches for both substance-related and other compulsive, repetitive behaviors, which some call addictions. At an individual level, labeling such behavior as addiction leads these behaviors "to grow because it excuses uncontrolled behaviors and predisposes people to interpret their lack of control as the expression of a disease that they can do nothing about" (Peele, cited in 39, 1426).

Yet other critics have questioned whether it is premature to consider IA as a separate diagnostic category. Shaffer et al. [11] argue that "empirical support for the construct validity of computer (and Internet) addiction has yet to emerge, (and) that defining the construct as a unique psychiatric disorder is therefore premature" (p. 162). Further, they contend that "in most cases, computer (and Internet) use may be symptomatic of other, more primary disorders" (p. 162). From this perspective, labeling IA "as if it were a new diagnostic entity may lead to the misdiagnosis of primary psychiatric disorders for which we have proven therapeutic interventions" [40, p. 890].

\section{Relationship of IA to other disorders}

In fact, IA has been found to be co-morbid with a number of other disorders including depression [20, 41], substance abuse [42], and sexual compulsivity [35], and Internet dependents are more likely than others to engage in activities such as online gambling and netsex [4, 22, 43, 44]. Personality factors associated with IA include loneliness [14, 20, 22, 23, 45, 46], shyness and social anxiety [13, 23, 24, 47].

\subsection{Preexisting pathology and IA}

However, there is considerable debate over the meaning of the relationship of IA with other disorders. As mentioned earlier, many contend that what has been labeled as IA is in fact symptomatic of other disorders. Limited evidence that those with IA had pre-existing problems is provided by a study in which individuals who met the criteria for IA who were given face-to-face (ftf) interviews using the Structured Clinical Interview for Diagnostic and Statistical Manual of Mental Disorders (SCID-IV). All 20 participants had at least one lifetime DSM [28] Axis 1 diagnosis in addition to IA with an average of five 
other diagnoses; over 2/3s (70\%) had a lifetime diagnosis of bipolar disorder, $85 \%$ had had previous mental health treatment, and $75 \%$ had been treated with psychotropic medications [27].

\subsection{IA and depression}

Those with IA are more likely than others to use the Internet to modulate negative moods; they use the Internet to escape pressures, when down, anxious, socially isolated and to control moods [22, 48]. Although this provides support for those who contend that Internet abuse is symptomatic of other problems such as depression, the direction of the relationship is not clear. Co-morbidity does not determine direction of the relationship. A number of other disorders are comorbid with depression including substance abuse, pathological gambling, sexual compulsivity, impulse control disorders, chronic loneliness and social anxiety $[28,35,49,50]$.

\subsection{Internet-enabled pathology}

The high incidence of online sexual activity (OSA) and gambling among those with IA suggests that the Internet is a new vehicle to act out pathology for those at risk; that is, they are Internet-enabled pathologies. Much research has explored online sexual activities and gambling pathology (e.g. 35, 51, 52]. It is probable that those who develop disturbances from their online behavior in these areas had pre-existing pathology [34]. However, Cooper et al. [35] argue that some would not have acted out pathologically without exposure to the unique characteristics of cybersex. Further, pathology may develop more rapidly online and the patterns of the development and expression of pathologies appear to differ online from offline [34].

\subsection{Specific vs. generalized IA}

Morahan-Martin [34] suggests differentiating between IA and Internet-enabled pathologies related to specific activities associated with established categories of psychopathology such as sexual paraphilias or pathological gambling which are acted out online. Similarly, Davis [21] advocates differentiating between those whose Internet abuse is associated with specific activities, which he calls specific pathological Internet use, and those who have a more generalized form of IA, which he calls generalized pathological Internet use, that is not linked to any specific activity, but to abuse of the Internet itself which results in negative consequences. Davis further argues that IA occurs when Internet users develop problems due to the unique communicative context of the Internet.

\section{IA and online social activities}

Davis' [21] assertion of the importance of online communication in the development of IA has much support. Even before formal research on IA began, commentators observed that the availability of changed social interactions on the Internet is a key contributor to the development of IA. Pavel Curtis, a computer 
scientist who in the early 1990s created an experimental MUD, (MultiUser Domain, a type of online interactive game) commented on the out-of-control behavior of some participants.

They're communication addicted. They're addicted to being able to go out and find people twenty-four hours a day and have interesting conversations with them. We're talking about people who spend up to seventy hours a week connected and active on a MUD. Seventy hours a week, while they're trying to put themselves through school.... These are very enticing places for a segment of the community. And it's not like the kinds of addictions that we've dealt with as a society in the past. If they're out of control, I think that's a problem. (Cited in [1], 1993).

Research consistently has supported that the unique social interactions made possible by the Internet play a major role in the development of IA [4, 15, 21-25, $30,41,53,54,55]$. Those with IA are more likely than other Internet users to use the Internet to meet new people, find emotional support, and talk to others with the same interests [22]. They use socially interactive activities such as chat rooms, newsgroups, interactive games more than others [13, 18-20, 22, 30, 53, $54,56]$.

Morahan-Martin and Schumacher [22] found that the social aspects of Internet use consistently differentiate those with IA from other Internet users, and conclude that for those with IA, "the Internet can be socially liberating, the Prozac of social communication" (p. 20). In their study, those with IA were more likely than others to report that their behaviors online as less socially inhibited. They were more likely to say that they are more themselves online, have more fun with people they know online, share intimate secrets online, and prefer online to face-to-face (ftf) communication. Internet abusers consistently reported increased social confidence online which enhanced their friendship network. They were more likely than others to report that they are friendlier and open up more to people online than in real life, that going online has made it easier to make friends, and that they have a network of online friends. In fact, those with IA were more likely to say that most of their friends they know from being online, and that their online friends understand them better than other people. Similarly, Leung [53] found anonymity, social ease online and social disinhibition are strong predictors of IA, while Whang et al. [20] found those with IA are more likely to reveal personal concerns to online friends and even to meet online friends ftf. Caplan [23] has hypothesized that users' preference for the social benefits available online is an important predictor of IA and based on his research concludes that "preference for computer-mediated social interaction, as opposed to face-to-face interaction, plays a role in the etiology, development and outcomes" of IA (p. 555). This will be discussed in more detail later.

\section{Loneliness and social anxiety and IA}

The preference for online over $\mathrm{ftf}$ interaction may be a key factor in the relationship between IA and both loneliness and social anxiety. Those who are chronically lonely and those who social anxious share many characteristics 
which may predispose them to develop IA. Both are apprehensive in approaching others, fearing negative evaluations and rejection. They tend to be self-preoccupied with their perceived social deficiencies, which leads them to be inhibited, reticent, and withdrawn in interpersonal situations and avoid social interactions [57-62].

The Internet is ideally suited for these individuals. Online social interactions are not face-to-face, often anonymous, and allow increased control which can alleviate self-defeating behavioral patterns and cognitions.

Research supports that social behavior of the socially anxious and lonely is enhanced online [24, 46, 63], and they are more likely than others to develop a preference for online over $\mathrm{ftf}$ social interaction, which is an important predictor of the development of IA $[25,64]$.

\section{An emerging theory of Internet abuse}

A number of theories have been proposed to explain IA. Some have perceived it as involving a deficiency in self regulation and impulse control and argued for a social-cognitive [65] or a biological basis [66]. Davis' cognitive-behavioral model of IA [21] argues that existing psychosocial problems such as loneliness and depression predispose some Internet users to exhibit maladaptive cognitions and behaviors that result in IA.

Caplan [23-25], in a series of studies, has expanded on Davis' [21] as well as others' theories and research $[22,46]$ and developed a model to explain IA which to date is the most comprehensive and empirically based. He has found that a very important cognitive aspect of IA is a preference for online, over ftf, social interaction (POSI), which he defines as "a cognitive individual difference construct characterized by beliefs that one is safer, more efficacious, more confident, and more comfortable with online interpersonal interactions and relationships than with traditional $\mathrm{ftf}$ social activities" [24, p. 629]. POSI is a significant mediator between psychosocial problems of loneliness and depression and negative outcomes associated with Internet use that are associated with IA [24].

A second critical factor is a social skill deficit in perceived social control, which is "an individual's competence at self-presentation, role-taking, and impression management in $\mathrm{ftf}$ interpersonal interactions" [25, p. 725]. Drawing on the literature on social anxiety, loneliness and their relationship to Internet use and abuse, Caplan [25] presents a model that hypothesizes that those who perceive themselves to have low self-presentational skill are more likely than others "to prefer online social interaction because they perceive their presentational skill in online social interaction to be greater than in $\mathrm{ftf}$ interaction" (p. 726). That is, those who lack confidence in their self-control and self-presentational skills experience social anxiety, and are more likely to turn to communication channels which minimize risks and enhance their capabilities. As discussed earlier, the Internet provides a "buffer for social interaction" $[67$, p. 332] where users can have greater control over their presentation of self, with less perceived risk in an anonymous environment which can decrease social 
inhibitions. Caplan further hypothesizes that compulsive Internet use mediates the influence of POSI on negative outcomes. That is, those who develop a preference for online over $\mathrm{ftf}$ communication will increasingly be unable to control impulses to use the Internet for communication. All hypotheses have been confirmed in Caplan's research with university undergraduates. Although preliminary, this theory provides an important framework for understanding the diverse factors associated with IA.

\section{Conclusions}

In the past decade, there has been a growing body of literature which has documented that worldwide some Internet users develop serious problems from their online behaviors, and many clinics have been set up to help these individuals. IA has been associated with a number of disturbances such as depression, loneliness and social anxiety. Some Internet-related problems are related to specific activities on the Internet such as the acting out of sexual paraphilias or compulsive gambling and are best thought of as new variants of established disorders or Internet-enabled pathologies. However, many users develop problems from what has been called a generalized form of IA. These users prefer socially interactive aspects of the Internet. Many are less inhibited in their online social interactions and find that they their social interactions are enhanced online compared to offline. This may account for the vulnerability to IA of those who are chronically lonely and socially anxious. A comprehensive model proposed by Caplan [25] suggests that those who lack self-presentational skill develop a preference for online over $\mathrm{ftf}$ communication which leads them to use online communication compulsively which in turn leads to IA. This model is particularly pertinent in explaining the high incidence of IA among those who are socially anxious and lonely. Critics have questioned whether IA exists and the validity of the existing constructs of IA. Some have questioned whether the Internet is inappropriately being blamed for problems which develop from its use and whether labelling individuals with IA obscures more appropriate diagnosis and treatment.

\section{References}

[1] Rheingold, H., The Virtual Community: Homesteading on the Electronic Frontier. Addison Wesley: Reading MA, 1993. http://www.rheingold.com/vc/book/5.html

[2] Turkle, S., Life on the Screen: Identity in the Age of the Internet. Simon \& Schuster: New York, 1995.

[3] Hamilton, K., \& Kalb, C., They log on, but they can't log off. Newsweek, 126 (25), p.60, 18 Dec.1995.

[4] Scherer, K., College life online: Healthy and unhealthy Internet use. Journal of College Student Development, 38, pp. 655-665, 1997.

[5] Young, K.S., Internet addiction: The emergence of a new clinical disorder. CyberPsychology and Behavior, 1, pp. 237-24, 1996. 
[6] Suler, J. Computer and cyberspace addiction. International Journal of Applied Psychoanalytic Studies, 1, pp. 359-362, 2004.

[7] South Korea plans more centres to treat Internet addiction, September 2005. Retrieved from Lexis/Nexis database.

[8] Beijing clinic treats Web addicts. Wired News, July 2004. http:/www.wired.co/news/culture/1,68081-0.html

[9] Grohol, J., Too much time online: Internet addiction or healthy social interactions. CyberPsychology and Behavior, 2, pp. 395-402, 1999.

[10] Mitchell, P., Internet addiction: Genuine diagnosis or not? Lancet, 355(9204), pp. 632, 2000.

[11] Schaffer, H. J., Hall, M. N., \& Vander Bilt, J., "Computer addiction": A critical consideration. American Journal of Orthopsychiatry, 70(2), pp. 162168, 2000.

[12] Walther, J. B., \& Reid, Larry D., Understanding the allure of the Internet. Chronicle of Higher Education, pp. B4-B5, 4 February 2000.

[13] Chak, K. \& Leung, L., Shyness and locus of control as predictors of Internet addiction and Internet use. CyberPsychology and Behavior, 7 (5), pp. 559-570, 2004.

[14] Nalwa, K. \& Anand, A.P., Internet addiction in students: A cause of concern. CyberPsychology and Behavior, 6 (6), pp.653-656, 2003.

[15] Pratarelli, M.E. \& Browne, B.L., Confirmatory factor analysis of Internet use and addiction. CyberPsychology and Behavior, 5(1), pp. 53-64, 2002.

[16] Simkova, B. \& Cincera, J.C., Internet addiction disorder and chatting in the Czech Republic. CyberPsychology and Behavior, 7, pp. 536-539, 2004.

[17] Tsai, C.C. \& Lin, S.S., Analysis of attitudes toward computer networks and Internet addiction of Taiwanese adolescents. CyberPsychology and Behavior, 4 (3), pp. 373-376, 2003.

[18] Chen, K., Chen, I. \& Paul, H., Explaining online behavioral differences: An Internet dependency perspective. Journal of Computer Information Systems, 41(3), pp. 59-63, 2001.

[19] Lin, S.S.J. and Tsai, C.C., Sensation seeking and internet dependence of Taiwanese high school adolescents. Computers in Human Behavior, 18, pp. 411-426. 2002.

[20] Whang, L.S., Lee, S. and Chang, G., Internet over-users' psychological profiles: A behavior sampling analysis on Internet addiction. CyberPsychology and Behavior, 6 (2), pp. 143-150, 2003.

[21] Davis, S., A cognitive-behavioral model of pathological Internet use. Computers in Human Behavior, 17, pp. 187-195, 2001.

[22] Morahan-Martin, J. and Schumacher, P., Incidence and correlates of pathological Internet use among college students. Computers in Human Behavior, 16, pp. 13-29, 2000.

[23] Caplan, S.E., Problematic Internet use and psychosocial well-being: Development of a theory-based cognitive-behavioral measurement instrument. Computers in Human Behavior, 18 (5), pp. 553-575, 2002. 
[24] Caplan, S.E., Preference of online social interaction: A theory of problematic Internet use and psychosocial well-being. Communication Research, 30(6), pp. 625-648, 2003.

[25] Caplan, S.E., A social skill account of problematic Internet use. Journal of Communication, 55, pp. 721-736, 2005.

[26] Shapira, N. A., Goldsmith, T.D., Keck, P., Khosla, U., \& McElroy, S., Psychiatric features of individuals with problematic Internet use. Journal of Affective Disorders, 57, pp. 267-272, 2000.

[27] Shapira, N., Lessig, M., Goldsmith, T., Szabo, S., Lazoritz, M., Gold, M., \& Stein, D., Problematic Internet use: Proposed classification and diagnostic criteria. Depression and Anxiety, 17, pp. 207-216, 2003.

[28] American Psychiatric Association (APA). Diagnostic and Statistical Manual (4th edition, text revision) (DSM IV-TR). Author, Washington, 2000.

[29] Nichols, L.A. \& Nicki, R., Development of a psychometrically sound Internet Addiction Scale: A Preliminary Step. Psychology of Addictive Behavior, 18, pp. 381-384, 2004.

[30] Young, K., Internet addiction: The emergence of a new clinical disorder. CyberPsychology and Behavior, 1, pp. 237-244, 1998.

[31] Orzack, M., Computer addiction: Is it real or virtual? Harvard Mental Health Letter, 15 (7), p. 8, January 1999.

[32] Treuer, T., Fabian, Z. and Furedi, J., Internet addiction associated with features of impulse control disorder: Is it a real psychiatric disorder? Journal of Affective Disorders, 66, p. 283, 2001.

[33] Griffiths, M.D., Internet addiction: Does it really exist? Psychology and the Internet: Intrapersonal, Interpersonal and Transpersonal Applications, ed. J. Gackenbach, Academic Press: New York, pp. 61-75, 1998.

[34] Morahan-Martin, J., Internet Abuse: Disorder? Symptom? Fiction? Alternative Explanations? Social Science Computer Review, Special Issue on Deviance on the Internet, 23, pp. 39-48, 2005.

[35] Cooper, A., Putnam, D, Planchon, L., \& Boies, S. Online sexual compulsivity: Getting tangled in the Net. Sexual Addiction and Compulsivity, 6, pp. 79-104, 1999.

[36] Jacobs, D., A general theory of addictions. Journal of Gambling Behavior, 2, pp. 15-31, 1986.

[37] Kubey, R., \& Csikszentmihalyi, M., Television addiction is no mere metaphor. Scientific American, 286 (2), pp. 79-86, February 2002.

[38] Milkman, H., \& Sunderwirth, S., Addictive processes. Journal of Psychoactive Drugs, 14, pp. 177-192, 1982.

[39] Jaffe, J., Trivializing dependence. British Journal of Addiction, 85, pp. 1425-1427, 1990.

[40] Huang, M.P. \& Alessi, N.E., Internet addiction, Internet psychotherapy. American Journal of Psychiatry, 153, p. 890, 1997.

[41] Young, K., \& Rodgers, R., The relationship between depression and Internet addiction. CyberPsychology and Behavior, 1, pp. 25-28, 1998. 
[42] Bai Y.M., Lin C.C. \&. Chen JY., Internet Addiction Disorder among clients of a virtual clinic. Psychiatric Service, 52 (10), p. 1397, 2001.

[43] Greenfield, D., Psychological characteristics of compulsive Internet use: A preliminary analysis. CyberPsychology and Behavior, 2, pp. 403-412, 1999.

[44] Young, K., What makes online usage stimulating: Potential explanations for pathological Internet use. Paper presented at the 105th Annual Convention of the American Psychological Association, Chicago, IL, August 1997.

[45] Kubey, R.W., Lavin, M.J., \& Barrows, J.R., Internet use and collegiate academic performance decrements: Early findings. Journal of Communication, 51 (2), pp. 366-382, 2001.

[46] Morahan-Martin, J. \& Schumacher, P., Loneliness and social uses of the Internet. Computers and Human Behavior, 19 (6), pp. 659-671, 2003.

[47] Pratarelli, M.E., Sex, shyness, and social Internet use. Paper presented at the $113^{\text {th }}$ Annual Convention of the American Psychological Association, Washington, D.C., August 2005.

[48] Anderson, K.J., Internet use among college students: an exploratory study. Journal of American College Health. 50(1), pp. 21-6, 2001.

[49] Becona, E, Lorenzo, M, \& Fuentes, M., Pathological gambling and depression. Psychological Reports, 78, pp. 635-640, 1996.

[50] Forsyth, D. \& Elliott, T. Group dynamics and psychological well being: The impact of groups on adjustment and dysfunction. The Social Psychology of Emotional Problems: Interfaces of Social and Clinical Psychology, eds. R. Kowalski and M. Leary, American Psychological Association: Washington DC, pp. 339-361, 1999.

[51] Griffiths, M.D., Internet gambling: Preliminary results of the first UK prevalence study. E-Gambling: The Electronic Journal of Gambling Issues (Issue 5), October 2001, http:/www.camh.net/egambling/issue5/research/griffiths article.html

[52] Griffiths, M. \& Parke, J., The social impact of Internet gambling. Social Science Computer Review, 20, pp. 312-320, 2002.

[53] Leung, L., Net-Generation Attributes and seductive properties of the Internet as predictors of online activities and Internet addiction. CyberPsychology and Behavior, 7 (3), pp. 333-348, 2004.

[54] Weiser, E.B., The functions of Internet use and their social and psychological consequences. CyberPsychology and Behavior, 4 (6), pp. 723-743, 2001.

[55] Yuen, C.N. \& Lavin, M.J., Internet dependence in the collegiate population: The role of shyness. CyberPsychology and Behavior, 7 (4), pp. 379-383, 2004.

[56] Johansson, A. \& Götestam, K.G., Internet addiction: Characteristics of a questionnaire and prevalence in Norwegian youth (12-18 years). Scandinavian Journal of Psychology, 45, pp. 223-229, 2004. 
[57] Bruch, M.A., Kalfowitz, N.G. and Pearl, L., Mediated and unmediated relationships of personality components to loneliness. Journal of Social and Clinical Psychology, 6, pp. 346-355, 1988.

[58] Burger, J.M., Personality (6 ${ }^{\text {th }}$ edition). Belmont CA: Wadsworth, 2004.

[59] Leary, M.R. \& Kowalsky, R.M., Social Anxiety. Guilford: New York. 1995 a.

[60] Leary, M.R. \& Kowalsky, R.M., The self-presentation model of social phobia. Social Phobia: Diagnosis, Assessment, and Treatment, eds. R.G. Heimberg, M.R. Liebowitz, D.A. Hope \& F.A. Schneier, Guilford: New York, pp.94-112, 1995b.

[61] Morahan-Martin, J., The relationship between loneliness and Internet use and abuse. CyberPsychology and Behavior, 2, pp. 431-440, 1999.

[62] Solano, C.H. \& Koester, N.H., Loneliness and communication problems: Subjective anxiety or objective skills? Personality and Social Psychology Bulletin, 15, pp. 126-133, 1989.

[63] Shephard, R. \& Edelmann, R.F., Reasons for Internet use and social anxiety. Personality and Individual Differences, 39, pp. 949-958, 2005.

[64] Ervin, B.A., Turk, C.L., Heimberg, R.F., Fresco, D.M. and Hantula, D.A., The Internet: Home to a severe population of individuals with social anxiety disorder? Journal of Anxiety Disorders, 18 (5), pp. 629-646, 2004.

[65] LaRose, R., Mastro, D., \& Estin, M.S., Understanding Internet usage: A social-cognitive Approach to uses of gratifications. Social Science Computer Review, 19, pp. 395-413, 2001.

[66] Schmitz, J.M., The interface between impulse-control disorders and addictions: Are pleasure pathway responses shared neurobiological substrates? Sexual Addiction \& Compulsivity, 12, pp. 149-168, 2005.

[67] Davis, R.A., Flett, G. L., \& Besser, A., Validation of a new measure of problematic Internet use: Implications for pre-employment screening. CyberPsychology and Behavior, 5, pp. 331-346, 2002. 